\section{La cultura visual en el proceso del tejido Puruhá}

Paolo Arévalo Ortiz *

Resumen: Desde la perspectiva de la etnohistoria, se abordan reflexiones teóricas acerca de la realidad histórica y cultural en la producción artesanal textil de la parroquia de Cacha. Históricamente está vinculada con la producción artesanal de textiles, destacándose por la técnica empleada para su elaboración, la cual ha permanecido relativamente constante a pesar de haber sido atravesada por discontinuidades que en ocasiones han intentado compatibilizarlas o hibridarlas, considerándose el uso de la vestimenta tradicional como expresión de identidad y elemento distintivo.

Palabras clave: Producción artesanal - textil - Puruhá

[Resúmenes en inglés y portugués en la página 159]

(*) Doctor en Diseño (Universidad de Palermo, Argentina). Máster Universitario en Dirección de Comunicación (Universidad Católica San Antonio de Murcia, España). Máster Universitario en Gestión de Información en Redes Sociales y Productos Digitales en Internet (Universidad de Extremadura, España). Licenciado en Diseño Gráfico (Universidad Nacional de Chimborazo, Ecuador). Profesor titular de la carrera de Diseño Gráfico de la Universidad Técnica de Cotopaxi.

\title{
Introducción
}

En la región sierra de Ecuador son escasos los pueblos que aún conservan formas de vestimenta precolombina, en su mayor parte incorporan rasgos de la hispana, creando una serie de formas claramente mestizas, en las que se puede observar la utilización de materiales, así como la combinación de figuras indígenas y españolas.

Si se habla de tradición textil en la nacionalidad kichwa Puruhá, a pesar de las diferentes rupturas históricas y culturales que han sufrido principalmente desde la colonia, ciertas características culturales aún se mantienen vigente. Es decir, "han permanecido relativamente constantes en el largo plazo [...] mantienen una presencia continua desde antes de la colonia”. (Rowe y Schelling, 1991, p. 29) 
Han ocurrido resignificaciones en la tradición de la vestimenta Puruhá, en efecto han sido atravesadas por discontinuidades que en ocasiones han intentado liquidarlas, compatibilizarlas o hibridarlas. Culturalmente hablando, no es sostenible la idea de una simple acumulación de tradiciones. (Rowe y Schelling, 1991, p. 31)

En la nacionalidad kichwa Puruhá no se conservan muestras de tejidos prehispánicos, teniendo en cuenta que dicha práctica de la elaboración textil era imprescindible en el desarrollo económico de las comunidades indígenas. Es preciso manifestar la utilización del término tradición, el cual remite a un referente o pauta cultural en base a diferentes elementos, tanto propios como ajenos, el mismo que entra en un proceso de interacción dinámica e histórica de tipo intercultural. A su vez "se presupone la existencia de un plano general o matriz cultural específica de cada cultura y cambiante a lo largo del devenir histórico, que articula y da sentido a lo diverso" (Bonfil, 1991, p. 172).

Con respecto al vestido de los Puruháes, los confeccionaban con fibra de cabuya y fibra de camélidos. La importancia de la cabuya para los Puruháes permitió comercializar en grandes proporciones, empleando las dos especies de cabuya que se encuentran en el medio: la blanca, y la negra llamada agave americana, o maguey. Esta planta se ha empleado en la elaboración de sogas de carga, vestidos, disfraces, alpargatas, sombreros, escobas, hamacas, alforjas, bolsos, shigras, costales, telas, tapetes entre otros. En la actualidad la cabuya todavía es empleada en varios tejidos Puruhá, como son la mama chumbi y paño chumbi. (Haro, 1977, p. 72, 73)

Dicho lo anterior, la vestimenta tiene como función proteger y cubrir el cuerpo, pero su estética llega a ser tan importante que se convierte en un elemento identificador y de expresión, mediante el cual una persona forma parte de un grupo. También, es diferenciadora de la posición social de cada individuo, dentro de una misma cultura marca la clase social dependiendo de la disponibilidad de recursos económicos, ya que refleja prestigio y riqueza, expresándose en prendas finas con adornos más costosos.

A fin de dar cuenta de la posición social del individuo, Bourdieu sostiene que la clase social no es una realidad de la sociedad, sino una categoría de la sociología, "la clase social [en sí] es inseparablemente una clase de individuos biológicos dotados del mismo habitus [...] todos los miembros de una misma clase tienen mayor número de probabilidades que cualquier miembro de otra de enfrentarse a situaciones más frecuentes" (Bourdieu, 2008). De igual modo, manifiesta "los que ocupan la misma posición tienen la misma probabilidad de tener el mismo habitus" (Bourdieu, 1987). Los individuos llevan incorporados habitus en función de su posición social. De allí que las clases estén formadas por individuos con el mismo habitus, o con alta probabilidad de que así sea. Esto hace que el habitus sea el eslabón entre las prácticas que genera y la estructura social que lo genera. (Martínez García, 1998, p. 14)

Desde un punto de vista objetivista, el concepto de clase social de Bourdieu se define como, un conjunto de individuos que comparten ciertas características estructurales, no solo grupos definidos por fronteras más o menos arbitrarias sobre una propiedad continua: ingresos, prestigio, etc., y que son iguales en ciertos aspectos relevantes. Con respecto a lo mencionado, hay una importante relación con la clase social. Weber define como un "grupo de individuos con expectativas similares debido a los recursos de que disponen y a su posición en el mercado de trabajo”. (Weber, 1922 en Martínez García 1998, p. 17) 
Sin embargo, el vestir depende de las condiciones específicas de cada grupo o comunidad, su estructura social y los materiales que puedan obtenerse del medio local, aunque de manera considerable los materiales se adquieren mediante diferentes sitios de comercialización. Lógicamente, esta función del tejido surge cuando la división social basada en factores de edad y sexo sustituye una división basada en el trabajo que cada individuo realiza. (Martínez Borrero y Sojos de Peña, 1982, p. 4)

\section{Cacha: lugar dedicado a la producción textil}

Cacha es una parroquia rural de población indígena, se encuentra ubicada en la provincia de Chimborazo, aproximadamente a $8 \mathrm{~km}$. de la ciudad de Riobamba, sus límites son al norte con San Juan y Licán, al sur con Cacha Obraje, San Antonio de Bashug, al este con Shilpalá y oeste con Amulá Cazaloma.

El movimiento indígena de Cacha se caracterizó por un proceso de revitalización étnica que permitió cambiar el sistema tradicional de dependencia de los comerciantes y caciques. El cambio de poder en Cacha involucró al descubrimiento de un pasado común y la creación de un pasado simbólico, semántico y físico separado de la parroquia de Yaruquíes, y la consecución de autonomía política como una parroquia.

Todos estos elementos facilitaron la invención de una identidad étnica común de los Cachas, entre los indígenas de diferentes comunidades y anejos. Esta identidad sirvió para confrontar la subordinación racial presente y sirvió de base para una entidad política distintiva y separada (Pallares, 2000).

La base de la identidad étnica es la relación con los otros, estructurada en la sociedad, de esta manera. Decir que la identidad étnica proviene de una relación, implica reconocer que es una formación cultural específica, dinámica que no está completamente definida, sino que siempre está en proceso de negociación (Pallares, 2000). Durante la Colonia, Cacha no pudo escapar a la estructura de explotación indígena introducida por los españoles. El poder colonial a través de dispositivos raciales y culturales estableció diferencias inconmensurables entre el colonizador y el colonizado.

El colonizado, mediante un violento proceso de poder fue subalternizado, el discurso colonial construyó al colonizado como una población degenerada racialmente, otorgándole un carácter fijo, estático y esencialista a las diferencias históricas, culturales y raciales. La colonialidad del poder propone focalizar el análisis de la construcción de las identidades, en el proceso en el cual se articulan las diferencias (Bhabha, 2007).

Las encomiendas en Cacha eran un derecho concedido por merced real a los beneméritos de las Indias, para cobrar y percibir los tributos de los indígenas que se les encomendaren por su vida y la de un heredero, conforme a la ley de sucesión, con cargo de cuidar del bien de los indígenas en lo espiritual y temporal y de habitar y defender las provincias donde fueren encomendados (Rueda, 1995).

La encomienda permitió el despojo de las tierras de las comunidades que durante el transcurso de los siglos XVI y primera mitad del XVII fue el mecanismo que canalizó la obligación de cumplir el tributo por parte de las comunidades indígenas. De tal forma se organizó la producción agropecuaria artesanal y aseguró la disponibilidad de mano de obra, 
además posibilitó el control y dominación ideológicos de los sojuzgados. Estos tributos eran canalizados por medio de la autoridad cacical, que poco a poco fue degenerando hasta desaparecer por completo alrededor del siglo XVIII, cuando dejó de ser necesaria para la colonia (Naranjo Villavicencio, 2002).

De esta manera, la encomienda resultaba una necesidad económica, lo que ocasionó que se defendieran en virtud de considerarse como sustento de los españoles, y políticamente, porque era el medio eficaz para mantener sujeta la tierra y obedientes a los indígenas.

Junto con las mitas, las encomiendas cumplían una función precisa a través del tributosalario. Con ellas se incrementaba la plusvalía generada por el trabajo indígena y, por otro lado, se facilitaba la apropiación del excedente de las comunidades en forma de alimentos, vestidos y sobre todo en la fuerza de trabajo. Consistía en una labor por turno llevada a efecto por millares de trabajadores, por enjambres de mitayos.

Los mitayos nunca se consideraron seres desgraciados: $1^{\circ}$ porque no estaban sometidos a un trabajo intensivo en la integridad de los días de sus vidas, sino por rigurosos turnos para que nadie trabajara más ni otros menos. $2^{\circ}$ Porque niños, mujeres, ancianos e inválidos no eran compelidos a prestar servicios pesados, por quedar a cargo de los adultos de 18 a 50, personas con buen estado de salud. Y $3^{\circ}$ porque en tanto se ocupaban en las mitas, el estado les daba alimento, chicha coca y hasta ropa a los que más destacaban. He ahí por qué los mitayos marchaban rumbo a las mitas tocando sus instrumentos musicales, cantando, danzando y exhibiendo flores en sus tocados. No arrastraban, pues, una vida miserable, ya que, además, mientras duraban las labores los mitayos no tocaban nada de sus pirguas para alimentarse, quedando dicho producto como un ahorro familiar. (Espinoza, 1997, p. 212)

Los mitayos hábiles comprendían entre 18 y 50 años, extraídos exclusivamente de los ayllus para la construcción y trabajo en obras del estado. El cual necesitaba productos alimenticios, textiles, artefactos, vías y puentes. Pero a esos productores directos les retribuía y redistribuía comidas, bebidas y otras cosas secundarias para que laboraran con satisfacción (Espinoza, 1997).

Las mitas representaban la facultad concedida al indígena para que con su trabajo pagara los tributos que sobre él recaían. Esta concesión de la corona española se convirtió en un recurso del conquistador, pues en la práctica todos los indígenas eran deudores de las cajas reales y en consecuencia podían ser tomados para el trabajo. En cambio, otros eran llevados de sus caseríos a las minas, donde trabajarían en la extracción de minerales a cambio de un bajo salario. A pesar de que estaba normado por la ley, el pago no se cumplía. González Suárez manifiesta que "la mita para las minas era, pues, una positiva sentencia de muerte [...] porque la muerte de los [indígenas] que iban a las minas les quitaban los brazos indispensables para la agricultura" González, 1970, p. 1742). Lo antedicho agravado porque los españoles, desde el primer momento, rehuyeron al trabajo directo en la tierra. En el siglo XVII se fomentaron la creación de obrajes, los cuales se constituyeron de gran 
importancia como los obrajes de San Pedro de Cacha, San Andrés, Punín, Yaruquíes, Macaje, Guasi, Chambo, Licto, Guano y Quimiag, donde se tejían paños, bayetas, lienzos de algodón y alfombras.

En Cacha, los obrajes eran el trabajo que los indígenas debían realizar en las fábricas de tejidos o hilados. Este trabajo también fue la muerte del indígena, frecuentemente morían atados a sus telares. La escasa y mala alimentación que recibían, el maltrato por parte de los capataces y administradores les causaba muchas enfermedades, en especial la tuberculosis y el escorbuto, de las que no eran curados (Costales, 1972).

A las cinco de la mañana el personal de los obrajes estaba en pie. El capataz o dirigente les hacía rezar la doctrina cristiana, misterios que ellos no comprendían, después de este velorio de rezos venía un desayuno, que apenas les remojaba la garganta. A las seis, los varones estaban clavados en sus telares. Las mujeres en cambio, unas lavando la lana, otras escogiendo la lana y un grupo numeroso hilando en diferentes clases de hilos, según el tejido que hacían, fino, mediano y grueso (Costales, 1972).

El obraje fue una de las actividades importantes dentro del aspecto industrial durante la colonia que "favoreció el desarrollo de un tipo especial de actividad agraria: la cría de ganado lanar y el surgimiento de un sector de comerciantes [...] los obrajes pertenecieron a la Corona" (Cueva, 1981, p. 57).

Es así como los varones indígenas comprendidos entre 18 y 50 años, con excepción de los curacas que eran los jefes de los pueblos o ayllus y sus familiares estaban obligados a pagar los tributos. Su fijación corría a cargo del juez visitador mediante un escrupuloso censo, y según la ley, un conocimiento concreto y justo de la condición económica de los encomendados; esos tributos se utilizaban para el mantenimiento y boato de los encomenderos.

Los encomenderos además de los obrajes también eran propietarios de los obrajuelos cuya producción era de menor calidad para abastecer el mercado local o para entregar productos semi-acabados a los obrajes, también existían los chorillos que eran unidades productivas de pequeño tamaño cuyos propietarios eran familias indígenas. Además, los campesinos eran considerados hombres sin palabra, sin pensamiento propio, sin capacidad iniciativa, ni de organización posible. "Todo estaba impuesto, cuando no reprimido, a nivel institucional de parte del Estado y sus servicios. Todo era acaparado por ese pequeño grupo blanco-mestizo [...] a los campesinos sólo les quedaba el miedo, el silencio, la sumisión, la domesticación" (Arrieta, 1984, p. 275).

En este contexto, la textilería paso a ser una de las principales especialidades productivas impuesta por los españoles, el obraje de San Pedro en Cacha, tuvo gran importancia a nivel nacional, se elaboraban sombreros, jergas, fajas, ponchos, capisayos - prenda de vestir corta que servía de capa-, y sombreros de lana. Es así que históricamente el pueblo de Cacha ha estado vinculado con la producción artesanal de textiles.

Asimismo, de su seno han surgido personajes importantes, líderes de los levantamientos indígenas más violentos que se recuerdan. El historiador Albornoz registra en los primeros cincuenta años de vida republicana iniciada en 1830, ocho levantamientos indígenas en la sierra, el noveno y mayor quizás, el que estuvo comandado por Fernando Daquilema de la comunidad Cacha-Queraj en 1871, quien al momento de mayor efervescencia de la 
revuelta fue declarado ñucanchi jatun apuj-nuestro gran señor, nuestro rey-. (Manosalvas, 2009; Arrieta, 1984)

Este hecho histórico, así como su líder Fernando Daquilema aún se mantienen en la memoria colectiva de la parroquia simbolizando la resistencia y liberación indígena. Esta serie de sucesos le otorga a Cacha una importancia histórica como zona de rebelión y resistencia (Pallares, 2000).

Luego de esta primera contextualización histórica, los cachas fueron representados, durante los siguientes 100 años, como grupos étnicos altamente referenciados en el papel de los mitos de linaje y de los recuerdos históricos. Asimismo fueron reconocidos por uno o varios rasgos culturales diferenciadores, como la religión, las costumbres la lengua o las instituciones. Dichas colectividades son doblemente históricas, porque no se trata sólo de que los recuerdos históricos sean esenciales para su continuación, sino que cada uno de los grupos étnicos es producto de unas fuerzas históricas específicas, por lo que están sujetos al cambio histórico e incluso a la disolución (Smith, 1997).

En este contexto y por un tema de síntesis argumental del artículo, se remitirá al siglo XX, y particularmente en la década de los años setenta, momento en que se dan cambios en las estructuras económicas y políticas en el pueblo de Cacha dando paso a la constitución de su organización mayor, la Federación de Cabildos Indígenas del pueblo Puruhá Cacha FECAIPAC constituida el 16 de septiembre de 1979, a través de una Ley de Comunas vigente desde 1937.

A partir de 1979, el pueblo de Cacha ha realizado profundos cambios en las comunidades y sus líderes como representantes del ayllu y ayllu llakta, al impulsar el proceso de fortalecimiento en su reconstitución con la conformación de la FECAIPAC, que tiene por objeto fortalecer el desarrollo y defender lo considerado como propio: recursos, derechos, identidad étnica y territorio. En virtud de lo mencionado anteriormente Cacha fue declarada parroquia rural con la ordenanza municipal No. 923 del 19 de agosto de 1980, por el Concejo Cantonal de Riobamba, en un documento que enfatizaba los valores culturales y étnicos distintivos, específicamente detallando en el artículo 5 lo siguiente: "La parroquia de 'Cacha' mantendrá la estructura y el ordenamiento que ha sido tradicional del lugar, manteniendo en todo lo que significan costumbres, viviendas, aspectos administrativos, lo que significan el origen de nuestra raza y de nuestra nacionalidad shiry-Puruhá. (Arrieta, 1984, p. 93)

El 25 de abril de 1981, el presidente de la República del Ecuador abogado Jaime Roldós Aguilera reconoce como parroquia civil a Cacha, esta declaratoria es importante para la parroquia, lo que ha permitido contar con una dinámica organizativa autónoma hasta la actualidad.

También es preciso mencionar que desde 1979 hasta el año 2000, la FECAIPAC su ente organizador funcionó sin ningún reconocimiento legal, es decir, de hecho. Luego de más de dos décadas de vida organizativa la federación divisó la necesidad de legalizarse y en coordinación con el Dr. Arturo León se preparó el proyecto de Estatuto de Gobierno Comunitario del Pueblo Cacha, aprobado en ese momento por el Ministerio de Bienestar Social, quien le otorgó la personalidad jurídica.

De este modo, fue el primer pueblo indígena de la nacionalidad kichwa Puruhá reconocido por el Estado ecuatoriano con estatuto gobernativo y personalidad propia. La orga- 
nización político-social, la disposición geográfica, el catolicismo, la economía monetaria, el idioma kichwa, español, los animales domésticos, las creencias y los rasgos de tipo colonial, han conformado una organización que es el resultado dinámico de la complejidad cultural en los Cachas (León, 2014; Janeta, 2015).

La parroquia rural de Cacha agrupa a 23 comunidades que son: Agua Santa, Amulá Chico Armenia, Amulá Cazaloma, Amula Rayoloma, Cacha, Cacha Huagshi, Cacha Obraje, Cacha Verdepamba, Cacha San Pedro, Cachatón San Francisco, Chacan Loma, Cahuiñag, Gaubug Inzaquil, Cruzada Hualiquiz, Machángara, Lemapamba, Pucará Quinche, San Antonio de Bashug, San Antonio de Murugallo, Shilpalá, Shihuiquis, San Miguel de Quera.

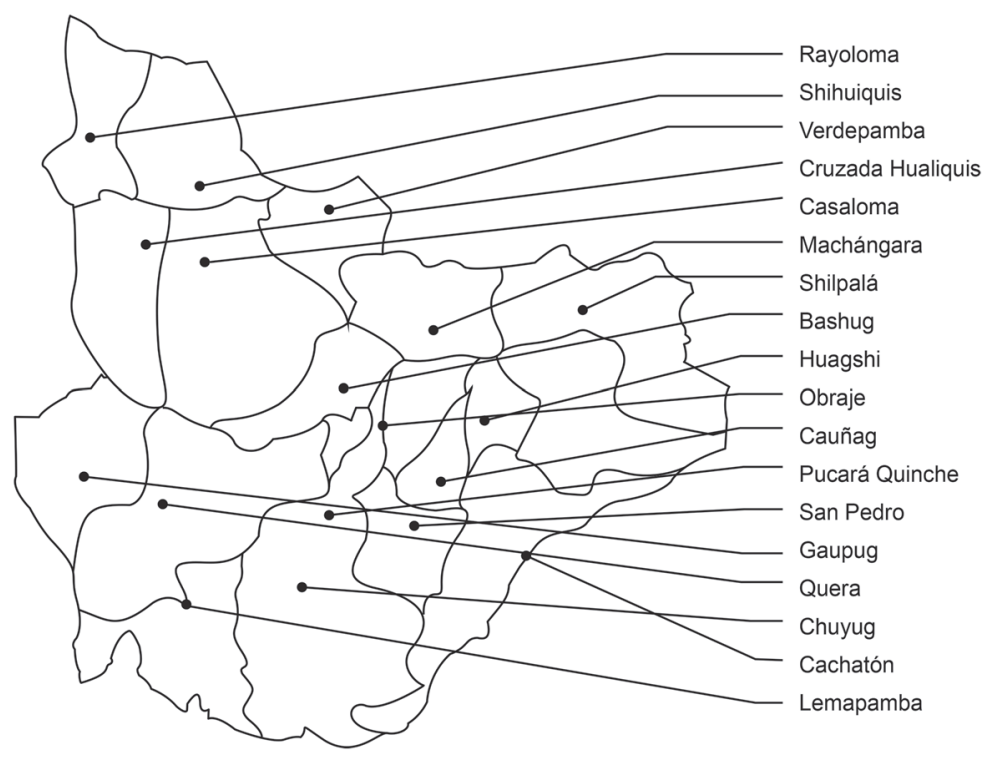

Figura 1. Mapa de comunidades de la parroquia de Cacha. Fuente: Elaboración propia

La comunidad de Cacha Machangará es el punto central donde se realizan las principales actividades organizativas y culturales. En 1984, el Padre Modesto Arrieta menciona que Cacha tenía 10000 habitantes, pero según datos del censo estadístico realizado por el Instituto Nacional de Estadística y Censos INEC en 2010, la población rural de Cacha es de 3.278 habitantes, constituyéndose el 1,40\% de la población del cantón Riobamba. Actualmente, el bilingüismo es parte de la realidad cultural de la comunidad. El idioma oficial de las comunidades de Cacha es el kichwa. 
Cacha al igual que distintas comunidades del sector rural del país se ha visto afectada por la migración, según la FECAIPAC la migración alcanza el 45\% de las familias en la parroquia. Los índices de pobreza son críticamente altos, al respecto el Sistema de Indicadores Sociales del Ecuador (SIISE) señala que la pobreza por necesidades básicas insatisfechas alcanza el 99,79\% de la población total de la parroquia, y el 82,99\% de pobreza extrema. Según estos datos casi toda la población de Cacha vive en condiciones de pobreza, situación que ha impulsado a familias enteras a la migración, la mayoría de los habitantes de la parroquia Cacha han migrado a la ciudad de Riobamba y otras ciudades como Guayaquil, Quito y Ambato. La motivación principal es el trabajo, consideran que no existen condiciones ni oportunidades en la parroquia para poder sostener a la familia y los gastos que esto representa. Migrantes, como se sabe, no cortan en modo alguno los lazos con la comunidad. (INPC, 2009; Burgos, 1970). Los lazos que perduran hacia la comunidad Smith denomina como "apego a ciertas extensiones de territorio, y a ciertos lugares dentro de dichas extensiones" (1997, p. 6). Lo importante para el grupo étnico Puruhá, más que la residencia o la posesión de la tierra, son esos vínculos o asociaciones sentimentales, en muchos casos también se trata de una tierra sagrada, la tierra de nuestros antepasados que es la inspiración a pesar de estar lejos durante un tiempo prolongado. Así pues, "una ethnie puede perdurar, aun cuando permanezca alejada de su patria durante mucho tiempo, gracias a una profunda nostalgia y apego espiritual" (Smith, 1997, p. 6). En parte de todo ese acervo y prácticas culturales se inscribe la elaboración de tejidos en Cacha. Ésta es una actividad que ha perdurado a través del tiempo otorgando identidad cultural, en sentido de continuidad que tienen las sucesivas generaciones de una "unidad cultural de población" en términos históricos y simbólicos (Smith, 1997, p. 8).

Es así que en la parroquia se han impulsado diversas iniciativas para fortalecer y mantener las técnicas de tejido que con el tiempo se habían debilitado. Parte de este fortalecimiento se comienza a articular el 23 de abril de 1975, día en el que se firmó el convenio entre la Conferencia Episcopal Italiana para América Latina (CEIAL) y el Centro de Promoción Artesanal de Yaruquíes. A partir de este convenio se decide cooperar en la realización de un programa de voluntarios, cuyo objetivo era la formación de obreros de construcción de casas en diversas ramas como carpintería y albañilería. Además, empezar un programa de alfabetización a través de cursos de educación, higiene sanitaria y puericultura. Cabe destacar que en función del foco propuesto también se desarrollaron cursos en telar como parte de este programa.

En tal virtud y para hacer realidad esta opción, en la iglesia de Riobamba organizaron equipos pastorales en Cacha. Conformado por un grupo de personas comprometidos para trabajar en la liberación integral del hombre, siguiendo un plan trazado por la Diócesis. El equipo estuvo compuesto por seis personas, un sacerdote, tres voluntarios italianos y dos campesinos. Para las obras de infraestructura el equipo contó con ayuda extranjera y de la diócesis, pero se mantenía el principio de exigir a los indígenas de la parroquia el $30 \%$ de aporte a través de mingas.

Con la experiencia de CEIAL (y los curso realizados en este marco) el padre Modesto Arrieta impulsa la organización de tejedores de Cacha y luego con el grupo de misioneros italianos en 1979 se promovió la creación del Centro Artesanal de Cacha, donde la prin- 
cipal tarea era la productividad de los tejidos. Ahí surge la elaboración de los primeros ponchos de Cacha, con el diseño iconográfico que se mantiene hasta la actualidad.

Continuando con este proceso, la FECAIPAC en 1992 efectuó en Cacha diversos talleres de socialización de las técnicas del tejido de ponchos, fajas, bayetas y sus diseños dirigidos a los jóvenes de las comunidades a través de jornadas de capacitación continua. Sami Ayriwa artesana Puruhá comenta "gracias a estos talleres y a la experiencia impulsada por el Centro Artesanal la tradición aún existe porque de no ya iba a perderse". (INPC, 2009, p.19)

En principio se realizaban talleres de costura y confección de camisas para las mismas mujeres haciéndolas bordar a mano y a máquina, de tal manera las familias podrían generar un ingreso económico. Así empezó la venta de diferentes artículos que las mujeres habían elaborado: bolsos de lana, orlón y cabuya, maletas, carteras, gorras, bufandas de lana de borrego y otras artesanías, incluso realizaban muñecas campesinas de lana con el niño cargado a la espalda o con el esposo vestido de poncho (Arrieta, 1984).

Para el taller de telares los misioneros del CEIAL intentaron mejorar el estilo de trabajo en la zona y hacerles notar que hay otras maneras de trabajar. Para este taller se recibió la ayuda de la Diócesis de Riobamba que proporcionó la primera instalación de telares y lana para empezar la producción. Por lo que el padre Arrieta menciona que:

Esta actividad está muy animada sobre todo por las nuevas ideas, buscando que ellos mismos elaboren nuevas ideas para la fabricación de bufandas, bolsos, ponchos antiguos que se estaban perdiendo, anacos, cobijas de pura lana bien abrigadas. Siempre buscamos incentivar la fabricación de prendas antiguas y dar valor al hecho de la hilada de lana y al uso de la misma para todos los trabajos. (Arrieta, 1984, p. 261)

Los primeros ensayos de producción textil artesanal lo realizaron con las mujeres de las comunidades de Obraje, Pucará, Guacshi y Machangará, a quienes para estimularles se les entregaba todo el material para el tejido a mitad de precio "las aprendices sentían gran satisfacción hacerse las prendas de vestir para sí mismas” (Arrieta, 1984, p. 265).

Del mismo modo trataban de usar las fibras de ovinos para dejar de usar la fibra de orlón, esto explica que se pretendía mantener la producción originaria de la zona y, por otra parte, las artesanías tienen mayor salida al ser fabricados con materiales originarios, además que un número apreciable de extranjeros prefieren estos trabajos antes que en otro material (Arrieta, 1984).

Este proyecto fue de importancia para la parroquia, contaba con locales específicos y con una dotación importante de implementos como telares para el tejido. Esta experiencia permitió socializar los saberes de los ancianos a los jóvenes incrementando el número de artesanos. De esa manera se logra revitalizar la tradición textil del poncho coco y algunos tipos de fajas. La producción y comercialización de tejidos y artesanías revitalizó las técnicas textiles y generó aspectos de carácter organizativo, cultural y religioso en las comunidades.

Sin embargo, la tejedora de la parroquia Cacha, María Guamán señala que cuando los misioneros italianos de CEIAL se fueron el proyecto se debilitó y dejó de funcionar. Al momento, la mayoría de tejedores expresan que fueron partícipes del Centro Artesanal Cacha y que en esta práctica adquirieron los conocimientos y técnicas de la textilería. 
En Cacha un pequeño porcentaje de familias mantiene la tradición textil, sobre todo las personas mayores son las que todavía tejen, por tal razón se mantienen los mismos procedimientos ancestrales de elaboración manual. Es característico que en la entrada de la vivienda los artesanos dispongan de un telar de cintura, denominado así por poseer un cinturón o faja que rodea la cintura del tejedor.

Respecto a la calidad, existe en diferentes comunidades el reconocimiento para los trabajos de Manuel Janeta, también conocido como -maestro Cacha o Taita Mañitu- diminutivo kichwa de su nombre, es considerado el máximo exponente de los tejidos en telares de la comunidad de Obraje, quien se inició en el oficio a los 22 años, cuando contrajo matrimonio con María Agustina Asqui. Al respecto Manuel de 86 años sostiene "yo trabajaba solamente bajo pedido, siempre vendía en mi casa, nunca fui a vender en otro lugar. $\mathrm{He}$ tejido ponchos para el presidente de la Republica Jaime Roldós cuando vino a la parroquialización de Cacha, Monseñor Proaño y otras personas importantes" (Janeta, 2016).

De la misma manera, Manuel menciona que antes se tejía con fibra de ovino, pero cuando llegaron las hermanas Lauritas influenciaron a la introducción del uso de orlón, el padre Estuardo Gallegos gestionó cursos en la parroquia, para poder enseñar la elaboración de prendas. En esa ocasión se enseñó a un grupo de personas de la comunidad a tejer el poncho coco, quienes al menos 10 jóvenes que se instruyeron con él continúan con la elaboración artesanal del poncho (Janeta, 2016).

En la actualidad, los artesanos de Cacha producen los tejidos por cuenta propia, en algunos casos comercializan a través de intermediados, venta directa y en ocasiones realizan bajo pedido.

\section{La vestimenta de los Puruháes}

Llegados a este punto es necesario mencionar que, debido a la modificación de las relaciones sociales en el marco de la Revolución Industrial y consolidación del Capitalismo en el siglo XIX, se aprecia con mayor rigor la separación genérica en los modos de vestir, "dejando los elementos decorativos relegados a lo femenino. La indumentaria femenina dio lugar al uso de accesorios recreando una estética femenina asociada al adorno y a lo decorativo como rasgo identitario que a primera vista se diferenciaba de lo masculino" (Zambrini, 2010, p. 131).

Otro aspecto por considerarse es la "división de los mundos privados y públicos" (Zambrini, 2010) lo femenino fue asociado al ámbito privado -decorativos-, en cambio, lo masculino fue relacionado con el trabajo y lo público. Dicho lo anterior, en la comunidad de Cacha se puede visibilizar la separación genérica en los modos de vestir, donde la mujer Puruhá mantiene el uso de accesorios decorativos como el tupu, fajas y collares. A continuación, se describe de manera detallada los modos de vestir entre los hombres y mujeres Puruháes (Haro, 1977).

La vestimenta de la nacionalidad Puruhá está determinada por factores medioambientales de la provincia de Chimborazo, manifestados en bajas temperaturas, en la disponibilidad de los materiales para su confección y en las condiciones socioeconómicas mencionadas 
anteriormente. Obviamente, la condición ambiental no solo se relaciona con la temperatura, pero en el caso del hombre y mujer Puruhá es determinante emplear una vestimenta que lo proteja del clima.

Entre los habitantes de las diferentes comunidades Puruhá, la elaboración del textil es considerada como sintetizadora de su cultura, por lo que ha sido reconocida nacional e internacionalmente debido a la diversidad de sus diseños, colores y modelos geométricos. Las mujeres tejedoras de Cacha se han especializado en la elaboración de cintas para sujetar el cabello, fajas y shigras, mientras que los hombres tienen especialidad en el tejido de ponchos, kawiñas y bayetas. Respecto a las técnicas usadas por los artesanos de Cacha para la elaboración de textiles continúa vigente en las comunidades de Cacha el método de hilar utilizando el huso, es común encontrar mujeres adultas que hilan mientras realizan actividades cotidianas con los animales. Por otra parte, las mujeres jóvenes no realizan esta actividad, por tal razón emplean fibras sintéticas como el orlón, para la elaboración del tejido.

Por otra parte, la indumentaria del hombre Puruhá está compuesta por una variedad de ponchos, pantalón, camisa blanca y sombrero. El poncho se conforma como una de las prendas masculinas más importantes en la indumentaria, "esta imprime un carácter representativo del status social en él que la lleva” (Martínez y Sojos de Peña, 1982, p. 23).

Los hombres de la comunidad de Cacha se diferencian del resto de los pueblos de la nación por el coco poncho o también llamado cacha poncho. Existen otros ponchos como la jerga, el sikipataponcho y el luto poncho. En la reconstitución del pueblo Cacha se ha considerado el resarcimiento de la vestimenta como uno de sus valores culturales. En el estatuto de la reconstitución del gobierno comunitario autónomo del pueblo Cacha se menciona: "todas las autoridades están obligadas por orden tradicional y por la comunidad a llevar puesta la vestimenta simbólica de autoridad en todos los acontecimientos, caso contrario entran en falta grave”. (León, 2014, p. 108)

Lo adultos mayores visten pantalón oscuro, camisa, sombrero y poncho de trabajo jerga o poncho coco dependiendo la ocasión. En cambio, los hombres jóvenes por lo general visten con pantalón y camisa, pero en lugar del poncho utilizan chompa y en algunos casos mantienen el sombrero. Sin embargo, para ocasiones especiales como: matrimonios, fiestas, asambleas comunitarias y fiestas en general incrementa la utilización del poncho coco. Para los hombres el poncho de varios colores, rojo, azul, negro, morado y blanco con y sin rayas negras es un signo de identidad étnica. Hasta la presente el uso de colores en el poncho en algunos casos define la afiliación de sus portadores a determinada comunidad parroquial. Tradicionalmente la mujer de Cacha viste anaco de color negro o azul, la bayeta es de colores como el rojo, verde, rosado y azul. Algo particular que se da en la mujer adulta, es el uso del $t u p u$, originalmente hecho de plata, aunque hoy se realizan imitaciones, el collar de mullos rojos, blancos, verdes, el sombrero apelmazado de fibra de ovino ha sido reemplazado por el sombrero de paño blanco o de diversos colores: café, negro según la ocasión. Para las ceremonias especiales es utilizado el sombrero blanco con el filo bordado y una cinta al costado. La manera de colocarse el anaco es muy singular en la mujer Puruhá de Cacha, en primer lugar, el anaco debe ser elaborado con fibras de ovino y tejida en telar, para sujetar utilizan tres tipos de fajas que son: la primera faja es la mama chumbi, luego va una segunda faja llamada kawiña chumbi y por último la faja que puede ser lama quingo o pura quingo. 
Por su parte, la kawina chumbi, prenda tejida en lana de borrego, utiliza generalmente los colores negro, verde, rojo y amarillo. Antiguamente estos se obtenían de pigmentos vegetales, en la actualidad se realiza a base de productos químicos. Las mujeres la usan para sostener el anaco, los varones, en cambio, dicen: "mientras más fajados, más fuertes". La faja femenina mide aproximadamente dos metros, en cambio, la masculina mide un metro; en las dos puntas llevan trenzas, el ancho es de acuerdo a la edad.

La mama chumbi o faja madre varía de las demás debido a su mayor anchura, ya que mide un metro de longitud. El ancho es variable y se lo hace de acuerdo a la edad, puede medir entre 10, 15 y $20 \mathrm{~cm}$. De color rojo oscuro o claro, los filos van combinados de verde, azul y fucsia. Esta prenda es utilizada por la mujer indígena como una segunda faja, el material que se utiliza para la elaboración de este tejido es lana de borrego, para que sea consistente y fuerte, de tal manera que no se doble mientras realizan trabajos agrarios (Turner, 1967). Cabe mencionar que la vestimenta de los actuales Puruhá de Cacha, es diferente a la utilizada tradicionalmente, es decir ha sufrido transformaciones a través del tiempo, lo que ha implicado una pérdida en las formas tradicionales de elaborarla. No se puede dejar de mencionar que la tradición textil de la parroquia de Cacha responde a los valores culturales que son transmitidos de generación en generación, lo que genera un proceso de aprendizaje y reproducción del conocimiento particular de la nacionalidad kichwa Puruhá.

Este aprendizaje se lo realiza por medio de la tradición oral, que cumple la tarea de explicar los orígenes de las cosas; por ejemplo, los inicios de fiestas de celebraciones existentes, en este sentido las tradiciones son apreciadas como el sentir del mundo, de la vida, de sí mismo (Zaruma, 2006, p. 181).

De modo que la vestimenta utilizada por hombres y mujeres Puruhá puede clasificarse como ropa de diario, festiva y ritual. Esta última hace referencia a la conducta formal que se relaciona con seres o poderes místicos, la misma que representa un conjunto de creencias y en algunos casos es utilizada para realizar rituales. Desde la perspectiva de Turner, el símbolo es la unidad mínima del ritual que aún conserva las características de la conducta ritual. De allí que según Bustos se convierte en un "factor de acción social, una fuerza positiva en un campo de actividad, donde la estructura y propiedades de un símbolo se convierten en las de una entidad dinámica, por lo menos dentro de su contexto de acción apropiado". (1970, p. 24)

En el fondo, la función de los mitos como aspectos precisos de los procesos sociales, trata de radicar, fundamentar y enlazar todo lo que existe en la vida que procede de una vida de orden sobrenatural; de tal manera que el mito permite expresar; sueños, visiones, creencias, que pone en contacto con sus enigmas y aspiraciones. Además en la nación Puruhá el mito es considerado una forma de pensamiento que relaciona el mundo material con el humano, y estos dos con el divino enmarcado con un carácter dramático (Zaruma, 2006, pp. 184, 185).

\section{Conclusiones}

Según la información que han proporcionado los tejedores y tejedoras de Cacha, los diseños tradicionales continúan vigentes en la elaboración del poncho coco y fajas, donde 
se encuentra mayor presencia de motivos zoomorfos que son parte fundamental en la vestimenta cotidiana de los Puruháes.

Mediante el trabajo etnográfico realizado en la comunidad de Cacha se puede visibilizar la diferencia entre el uso de la vestimenta de las personas más adultas y los jóvenes. La vestimenta en la actualidad es más ligera, por la escasez de recursos los trajes son más económicos, a la vez los jóvenes buscan prendas que combinen con la moda y tradición. De esta manera que el poncho es considerado como elemento indispensable en la vestimenta cotidiana de la nacionalidad Puruhá.

En cuanto a la producción textil puruhá a pesar de las diferentes rupturas históricas y culturales que ha sufrido, principalmente desde la colonia, ciertas características del tejido aún se mantienen vigente, es decir, han permanecido relativamente constantes a largo plazo, a pesar de haber sido atravesadas por discontinuidades que en ocasiones han intentado compatibilizarlas o hibridarlas. Es así que la transformación modernizadora del tejido en las comunidades de la nacionalidad puruhá, responde al criterio del abandono de la vestimenta tradicional no sólo como indicador de pertenencia a una comunidad, sino también como signo distintivo y de identificación de la condición indígena.

Por otro lado, la importancia del vestido y su uso expresa de manera general un modelo de sociedad. De hecho, algunas comunidades que pertenecen a la nacionalidad kichwa puruhá conservan vestidos que los distingue e identifica. Tal es el caso particular de la parroquia de Cacha, donde la vestimenta se considera como valor cultural, es así como en el estatuto del gobierno comunitario se menciona que todas las autoridades están obligadas por orden tradicional y por la comunidad a llevar puesta la vestimenta simbólica de autoridad en todos los acontecimientos, caso contrario entran en falta grave.

Del mismo modo en la parroquia se han impulsado diversas iniciativas para fortalecer y mantener las técnicas de tejido. Uno de los sucesos relevantes es la que generó el padre Modesto Arrieta impulsando la organización de tejedores de Cacha, donde la principal tarea era la productividad de los tejidos. Se ha podido constatar que un pequeño porcentaje de familias todavía mantiene la tradición textil, sobre todo las personas de mayor edad conservan procedimientos ancestrales de elaboración manual.

Los textiles elaborados por los puruháes además de ser objetos utilitarios también son de transmisión sociocultural cargada de valores estéticos y sociales. La cultura visual que emerge del tejido se relaciona con los hechos visuales del tejedor, que establece la transmisión de información histórica, de modo tal que conserva y fortalece la identidad de los pueblos manteniendo valores y códigos simbólicos a partir de los que se recrean y transmiten mensajes.

Por otra parte, la permanencia del diseño iconográfico se considera de los animales como; camélidos, aves, águilas, jaguares y serpientes debido a que eran considerados seres supremos y mitológicos. En cambio, en la agricultura se da especialmente de plantas y granos, además se hace referencia a la luna y el sol, las montañas y el agua puesto que son elementos fundamentales dentro de su vida cotidiana. A consecuencia de aquello se realizan abstracciones de cada uno de los elementos para generar íconos con características y propiedades que generan identificación cuando es plasmado en un textil, ya que continuamente la abstracción de los íconos se origina a partir de las formas básicas como: el círculo, 
cuadrado y triángulo, que al momento de unirlos o repetirlos forman una composición identificable.

Se puede decir que la cromática ha sido un elemento importante para la transmisión de mensajes, mediante el color se permite transmitir mensajes, emociones y experiencias, las cuales al momento de conjugarlas con formas el valor significativo crece y transmite una mayor cantidad de mensajes. De ahí que, este artículo haya explorado cómo la visualidad desempeña un papel relevante en el proceso de concepción del diseño textil en la nacionalidad kichwa puruhá.

\section{Lista de referencias bibliográficas}

Arrieta, M. (1984). Cacha, raíz de la nacionalidad ecuatoriana. Quito: Banco Central del Ecuador (BCE).

Bhabha, H. (2007). El lugar de la cultura. Ediciones Manantial.

Bonfil, G. (1991). La teoría del control cultural en el estudio de procesos étnicos. Estudios sobre las culturas contemporáneas, IV(12).

Bourdieu, P. (1987). ¿What makes a social class? On the theoretical and practical existence of groups. 32, 1-17.

Bourdieu, P. (2008). El sentido práctico. Madrid: Siglo XXI de España Editores.

Burgos Guevara, H. (1970). Relaciones interétnicas en Riobamba: Dominio y dependencia en una región indígena ecuatoriana. Quito: Instituto Indigenista Interamericano.

Bustos, G., y Pilco, M. (1970). Chumbo diseño de fajas. Riobamba: Abya Yala.

Costales Cevallos, A. (1972). Historia de Riobamba y su Provincia. Casa de la Cultura Ecuatoriana.

Cueva, A. (1981). Entre la ira y la esperanza. Cuenca: Casa de la Cultura Ecuatoriana.

INPC (2009). Tradición textil de la parroquia Cacha, expresión de su identidad. Instituto Nacional de Patrimonio Cultural, Riobamba.

Espinoza Soriano, W. (1997). Los incas. Economía, sociedad y Estado en la era del Tahuantinsuyo. Amaru Editores.

González, F. (1970). Historia general de la República del Ecuador. Quito: Casa de la Cultura Ecuatoriana.

Haro, S. (1977). Puruhá: Nación Guerrera. Quito: Editora Nacional.

Janeta, M. (23 de Agosto de 2016). Tejido de ponchos. Doctorado en Diseño. (P. Arévalo, Entrevistador) Cacha Obraje.

Janeta, P. (2015). Cosmovisión y Sabiduría Puruwa. Riobamba: Unidad Educatia Pachayachachic.

León, A. (2014). Territorio y Gobierno Comunitario. Quito: Empresdane Gráficas Cía. Ltda.

Manosalvas, M. (2009). Gestión de proyectos productivos comunitarios. Entre la tradición y el mercado.

Marco, R., y Moreno, S. (1995). Cosmos hombre y sacralidad: Lecturas dirigidas de antropología religiosa. Cayambe: Abya-Yala.

Martínez Borrero, J., y Sojos de Peña, D. (1982). Cuadernos de Arte Popular: El traje popular ecuatoriano. Cuenca: Centro Interamericano de artesanías y artes populares. 
Martínez García, J. (1998). Las clases sociales y el capital en Pierre Bourdieu. Un intento de aclaración. Salamanca: Materiales de Trabajo, serie análisis Universidad de Salamanca Departamento de Sociología.

Naranjo Villavicencio, M. (2002). La Cultura Popular en el Ecuador: Tomo IX Manabí. II(1).

Pallares, A. (2000). Bajo la sombra de Yaruquies: Cacha se reinventa. Quito: Andrés Guerrero, compilador, Etnicidades, FLACSO-ILDIS.

Rowe, W., y Schelling, V. (1991). Memory and modernity: Popular culture in Latin America. Verso Books.

Smith, A. (1997). El fundamento étnico de la identidad nacional. La identidad nacional.

Turner, V. (1967). The forest of symbols: Aspects of Ndembu ritual. Cornell University Press.

Zambrini, L. (2010). Producto de la modificación de las relaciones sociales en el marco de la Revolución Industrial y consolidación del Capitalismo. Nomadías(11), 130-149

Zaruma Quizhpilema, V. (2006). Wakanmay, aliento sagrado: perspectivas de teología india: una propuesta desde la cultura cañari. Quito: Abya Yala.

\begin{abstract}
From the perspective of ethnohistory, it is adrressed the theoretical reflections about the historical and cultural reality in the textile handicraft production of the parish of Cacha. It is historically linked to the traditional production of textiles, highlighted by the technique used for its production, which has remained relatively constant despite being crossed by discontinuities, that have sometimes tried to make compatible or hybridize them, considering the use of traditional clothing as expression of identity and distinctive element.
\end{abstract}

Keywords: Handicraft production - textile - Puruhá

Resumo: Desde a perspectiva da cultura, a reflexão sobre as teorias sobre a cultura e a cultura cultural da produção artesanal da paróquia da Cacha. Históricamente Cacha é relacionado com a produção artesanal de têxteis, destaca- se pela técnica empleada para a sua elaboração. A técnica permaneceu relativamente constante apesar de ter sido atravessado pelas descontinuidades que em ocasiões eles temtaran de fazer compatível ou hibridizar, considerando o uso de roupas tradicionais como uma expressão de identidade e elemento distintivo.

Palavras chave: Produção artesanal - textil - Puruhá

[Las traducciones de los abstracts fueron supervisadas por el autor de cada artículo] 